Tropical Journal of Pharmaceutical Research April 2020; 19 (4): 739-744

ISSN: $1596-5996$ (print); 1596-9827 (electronic)

(C) Pharmacotherapy Group, Faculty of Pharmacy, University of Benin, Benin City, 300001 Nigeria.

Available online at http://www.tjpr.org

Original Research Article

http://dx.doi.org/10.4314/tjpr.v19i4.9

\title{
Tanshinone IIA suppresses fibrosis induced by high glucose conditions in HK-2 cells via inhibition of extracellular matrix deposition, reduction of oxidative stress, and inhibition of epithelial to mesenchymal transition
}

\author{
Xi Zhao1, Yao-Guang Wang ${ }^{1 *}$, Xi-kai Yang ${ }^{2}$, Man Li $^{3}$, Shi-Jie Liu², Tong-Yan \\ Zhang $^{4}$, Yi-Qi Wang ${ }^{1}$ \\ ${ }^{1}$ Nephropathy Department, First Teaching Hospital of Tianjin University of Traditional Chinese Medicine, Tianjin 300112, \\ ${ }^{2}$ Tianjin University of Traditional Chinese Medicine, Tianjin 301617, ${ }^{3}$ Tianjin Beichen District Chinese Medicine Hospital, Tianjin \\ 300000, ${ }^{4}$ Second Hospital Affiliated to Tianjin University of Traditional Chinese Medicine, Tianjin 300150, PR China
}

*For correspondence: Email: yaoguangwa@163.com; Tel: +86-022-27986573

Sent for review: 5 October 2019

Revised accepted: 24 January 2020

\begin{abstract}
Purpose: To investigate the anti-fibrotic effects of tanshinone IIA (TS) on renal tubular epithelial cells (HK-2 cells) under high glucose conditions and their related molecular mechanism(s) of action.

Methods: After treatment with TS $(6 \mu \mathrm{g} / \mathrm{mL})$ for $24 \mathrm{~h}$, the morphology of HK-2 cells stimulated by high glucose was observed under the microscope. Additionally, potential mechanisms related to the antifibrosis effects of TS were evaluated using western blotting assay and quantitative real time PCR (qRT$P C R$ ), including transforming growth factor (TGF) $\beta 1, \alpha$-smooth muscle actin ( $\alpha$-SMA), heme oxygenase 1 (HO-1), laminin (LN), fibronectin (FN), and E-cadherin (E-cad).

Results: A high-glucose culture environment induced fibrosis of HK-2 cells, as indicated by changes in cell morphology. The anti-fibrotic effects of TS were mainly associated with a decrease in the expression levels of TGF- $\beta 1, \alpha-S M A$ and $L N$, while the expression of E-cad increased. These results also revealed that TS increased the expressions of HO-1.

Conclusion: The findings suggest that TS suppresses fibrosis caused by high glucose in HK-2 cells by inhibiting extracellular matrix deposition and epithelial-mesenchymal transition and by reducing oxidative stress. Further investigations are needed to evaluate the clinical application of this compound in diabetic nephropathy.
\end{abstract}

Keywords: Tanshinone IIA, Diabetic nephropathy, HK-2 cells, Fibrosis

This is an Open Access article that uses a fund-ing model which does not charge readers or their institutions for access and distributed under the terms of the Creative Commons Attribution License (http://creativecommons.org/licenses/by/4.0) and the Budapest Open Access Initiative (http://www.budapestopenaccessinitiative.org/read), which permit unrestricted use, distribution, and reproduction in any medium, provided the original work is properly credited.

Tropical Journal of Pharmaceutical Research is indexed by Science Citation Index (SciSearch), Scopus, International Pharmaceutical Abstract, Chemical Abstracts, Embase, Index Copernicus, EBSCO, African Index Medicus, JournalSeek, Journal Citation Reports/Science Edition, Directory of Open Access Journals (DOAJ), African Journal Online, Bioline International, Open-J-Gate and Pharmacy Abstracts

\section{INTRODUCTION}

Diabetic nephropathy (DN) is a chronic microvascular complication of diabetes mellitus (DM). Approximately one-third of diabetic patients eventually develop DN, however, the related pathogenesis has not yet been clarified. DN lesions commonly include damage to the glomerulus, renal blood vessels, and renal tubules. Early glomerular is glomerulosclerosis 
includes glomerular hypertrophy, basement membrane thickening, and extracellular matrix (ECM) accumulation [1]. It has been reported that epithelial-mesenchymal transition (EMT) is a key factor in transforming renal tubular epithelial (HK-2) cells into fibroblasts [2]. a-Smooth muscle actin ( $\alpha-S M A)$ which is a significant bio-marker of interstitial cells would be significantly upregulated, and it is commonly regulated by the signaling pathways of transforming growth factor (TGF) $\beta /$ Smad and wnt/ $\beta$-catenin [3]. Therefore, $\alpha-S M A$ and TGF- $\beta 1$ have beneficial effects on understanding the progress of EMT. Furthermore, oxidative stress can also be considered as a central link in the pathogenesis of DN, and heme oxygenase-1(HO-1) is a sensitive indicator of oxidative stress.

Accumulating scientific reports have revealed lots of extracts or compounds from natural herbal medicines that have medicinal properties for the prevention or treatment of diabetes mellitus and its complications [4,5]. Tanshinone IIA (TS), a medicinal component of Radix Salviae Miltiorrhizae, has a protective effect on the heart [6], is mainly used for the treatment of cardiovascular and cerebrovascular diseases. Currently, TS has been found to act as an antioxidant, reducing the injury of ischemia and reperfusion $[7,8]$. Interestingly, it has also been reported that TS show protective effects on diabetic nephropathy [5]; however, the molecular mechanisms involved are still unclear. Thus, in this study, we aimed to explore the anti-fibrotic effects of TS on HK-2 cells (under high glucose conditions) and the molecular mechanisms involved, providing evidence for further research regarding TS in DN treatments.

\section{EXPERIMENTAL}

\section{Chemicals and reagents}

TS was obtained from Zrbiorise (Shanghai, China); MEM- $\alpha$ was from Gibco (Grand Island, USA); FBS was from HyClone (California, USA); MTT and BCA kits were from Beyotime (Shanghai, China); glucose was from Sailboat Co. Ltd. (Tianjin, China); the TIANScriptII RT Kit and SYBR Green were from Tiangen Biotech Co. Ltd. (Beijing, China); antibodies against TGF $\beta 1$ (ab119558), a-SMA (ab32575), HO-1 (ab204524), E-cad (ab197751), FN (ab32419) and LN (ab11575) were from Abcam Biotechnology (Cambridge, UK).

\section{Cell culture}

The $5-10^{\text {th }}$ generation cells of HK-2 cells (Pinosin Biotech Co. Ltd, Wuhan, China) were cultured in MEM- $\alpha$ added with $10 \%$ FBS, penicillin and streptomycin $\left(37^{\circ} \mathrm{C}, 5 \% \mathrm{CO}_{2}\right.$ and $95 \%$ air).

\section{Cytotoxicity assays of TS}

Digested cell suspensions were put into 96-well plates, and edge holes were filled with sterile PBS. TS solution at different concentrations (1, $3,5,8,10,20$, and $40 \mu \mathrm{g} / \mathrm{mL}$ ) was then added to the 96-well cell culture plates, after which the MTT solution was added. Finally, the absorbance of each well was determined at OD $490 \mathrm{~nm}$ to calculate cell viability. The $\mathrm{IC}_{50}$ of TS at $6 \mu \mathrm{g} / \mathrm{mL}$ was selected because of its low cytotoxicity on HK-2 cells.

\section{Fibrosis in HK-2 cells caused by high glucose}

Non-fibrotic HK-2 cells without glucose but treated with the different concentrations of TS listed above were considered mock cells, while cells exposed to glucose alone were used as control cells. HK-2 cells treated with both glucose and $6 \mu \mathrm{g} / \mathrm{mL}$ of TS were considered TS-treated cells. After rinsing the cells, a solution of 30 $\mathrm{mmol} / \mathrm{L}$ glucose was added to the culture plate and cultured for $24 \mathrm{~h}$ as control groups. After treating with TS $(6 \mu \mathrm{g} / \mathrm{mL})$, cells were observed under a microscope.

\section{qRT-PCR assay}

Total RNA was extracted with the TRIzol reagent. Reverse transcription into cDNA was performed using the TIANScriptll RT Kit. RTqPCR was conducted using the Applied Biosystems $(\mathrm{ABI})$ real-time $\mathrm{PCR}$ system (CA, USA) to determine the mRNA expression of TGF- $\beta 1, H O-1, \alpha-S M A, F N, L N$, and E-cad in HK-2 cells. The procedure was performed at 95 ${ }^{\circ} \mathrm{C}$ for $10 \mathrm{~s}$, at $58^{\circ} \mathrm{C}$ for $30 \mathrm{~s}$, and at $72{ }^{\circ} \mathrm{C}$ for 30 $\mathrm{s}$ (40 cycles).

\section{Western blotting assay}

Cell proteins were collected, and the protein contents were determined using the BCA kits. Based on protein quantification, proteins were added to the protein gel electrophoresis sample buffer, mixed gently, denatured at $95{ }^{\circ} \mathrm{C}$ for 10 min, and immediately inserted into ice. The proteins were then transferred onto PVDF membranes (Millipore, USA) by electroblotting. The PVDF membranes were blocked with a blocking solution, after which they were cultured overnight at $4^{\circ} \mathrm{C}$ with antibodies against TGF $\beta 1$ (dilution 1:1000), a-SMA (dilution 1:1000), HO-1 (dilution 1:1200), E-cad (dilution 1:1500), FN (dilution 1:1000), and LN (dilution 1:800). 
Subsequently, the proteins were incubated with a secondary antibody at a dilution of 1:3000. Grayscale values were obtained using Image $\mathrm{J}$ software and the levels of relative proteins were evaluated by comparing the gray value of the given proteins with the levels of $\beta$-actin.

\section{Statistical analysis}

Data were expressed as mean $\pm S D$. The statistical differences were carried out by the ANOVA followed by LSD using SPSS 17.0 software for windows. $P<0.05$ was considered as statistically significant.

\section{RESULTS}

Fibrosis is induced by high glucose environment in HK-2 cells

Regarding the morphology of HK-2 cells, we observed round or polygonal cells that showed a "paving stone" (Figure $1 \mathrm{~A}$ ). In HK-2 cells stimulated with high glucose levels, we observed that renal tubular epithelial cells lost their intrinsic morphology, resembling a long spindle-like fibroblast, and that the nucleus also showed a spindle-like shape (Figure $1 \mathrm{~B}$ ).
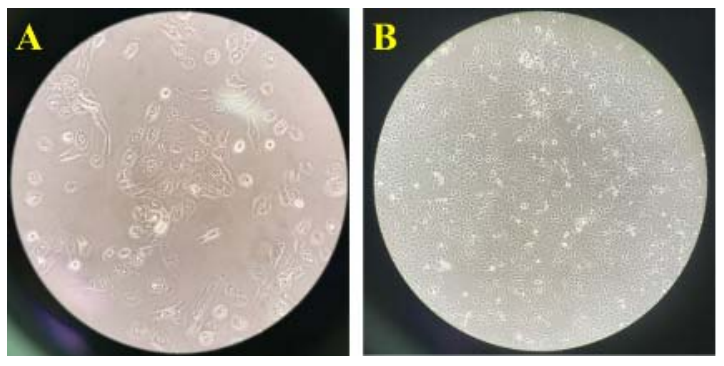

Figure 1: Morphology of (A) Mock HK-2 cells and (B) HK-2 cells stimulated with glucose

\section{Effects of TS on TGF- $\beta 1$ and phenotypic transformation}

Compared to control cells, TS-treated cells showed reduced levels of TGF- $\beta 1$, $\alpha-S M A$. Similarly, the western blotting results (Figure 3) showed that, in TS-treated cells, the expression levels of TGF- $\beta 1$ and $\alpha$-SMA reduced, but levels of E-cad increased $(p<0.05)$.

\section{Effect of TS on ECM}

Furthermore, the RT-qPCR assay was used to evaluate the effect of TS on the expressions of $\mathrm{FN}$ and LN mRNA. As can be seen from Figure 4 , the expression levels of FN and LN mRNA in TS-treated cells significantly decreased ( $p<$ 0.05). Similarly, the western blotting showed that the expression of LN in TS-treated cells also decreased ( $p<0.05$; Figure 5).

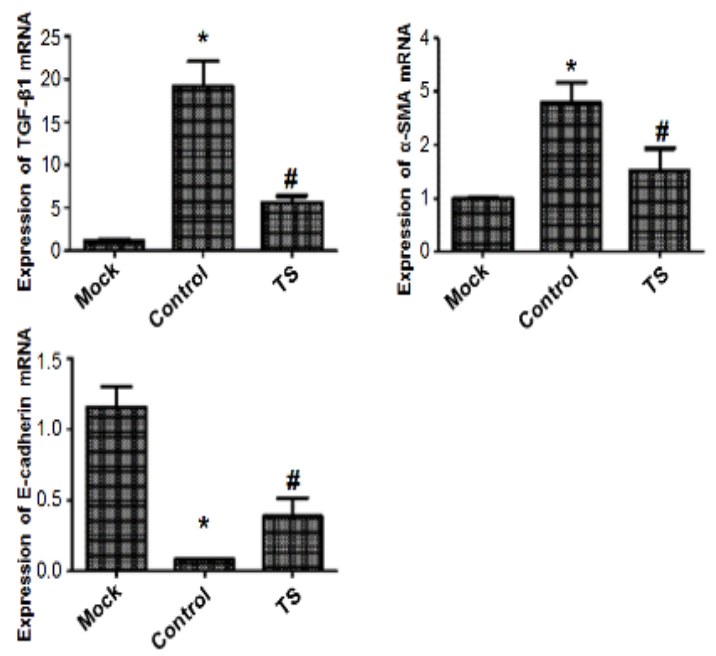

Figure 2: The mRNA expression of TGF- $\beta 1, \alpha-S M A$ and E-cad in HK-2 cells. ${ }^{*} P<0.05$ vs. mock group; ${ }^{\#} p$ $<0.05$ vs. TS group
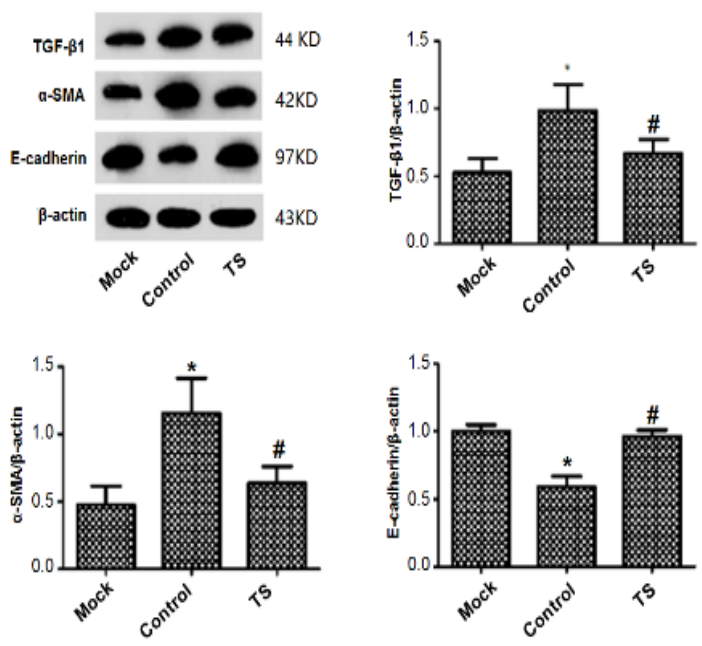

Figure 3: The protein expression of TGF- $\beta 1, \alpha-S M A$ and E-cad in HK-2 cells. ${ }^{*} P<0.05$ vs. mock group; ${ }^{\#} p$ $<0.05$ vs. TS group
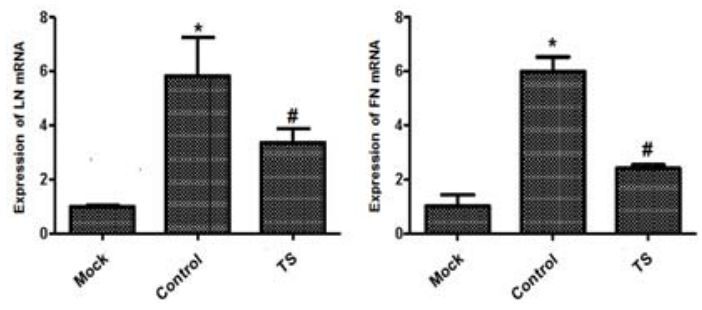

Figure 4: The mRNA expression of $\mathrm{LN}$ and $\mathrm{FN}$ in HK2 cells. ${ }^{*} P<0.05$ vs. mock group; ${ }^{\#} p<0.05$ vs. TS group 

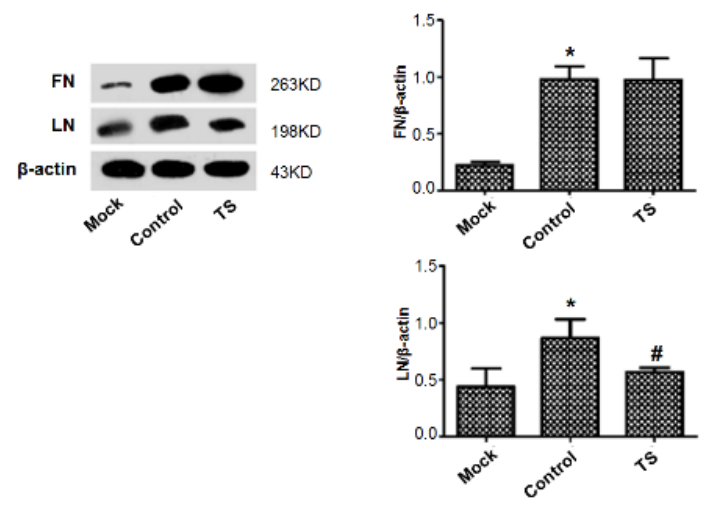

Figure 5: Protein expression of $\mathrm{LN}$ and $\mathrm{FN}$ in HK-2 cells. ${ }^{*} P<0.05$ vs. mock group; ${ }^{\#} p<0.05$ vs. TS group

\section{Effects of TS on HO-1 expression}

These results exhibited that the expression level of HO-1 increased after treatment with high glucose levels, but showed even higher levels in TS-treated cells $(p<0.05 ;$ Figure 6). Furthermore, the western blotting results showed the same results $(p<0.05)$.
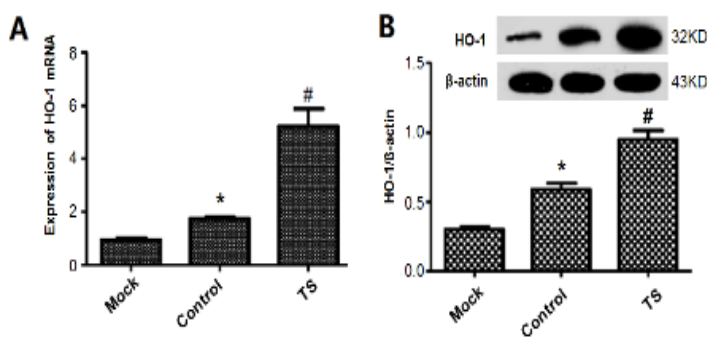

Figure 6: The mRNA $(A)$ and protein $(B)$ expression of HO-1 in HK-2 cells. ${ }^{*} P<0.05$ vs. mock group; ${ }^{\#} p<$ 0.05 vs. TS group

\section{DISCUSSION}

In the progression of DN to ESRD, symptoms such as the decrease in glomerular filtration rate (GFR) and fibrosis of glomeruli, tubules, and interstitium are particularly important $[9,10]$; hence, reducing or blocking the development of fibrosis is essential in the treatment of DN.

Transforming growth factor- $\beta 1$ is essential in renal fibrosis as it is a key cytokine in glomerulosclerosis [11]. TGF- $\beta 1$ is also a key growth factor in the process of fibrosis, and the accumulation of ECM, where the expression level of TGF- $\beta 1$ in glomerular mesangial cells was enhanced under high glucose conditions $[12,13]$. The necessity of Smad3 for TGF- $\beta 1$ induced EMT has been confirmed [14]. Under stress conditions, renal tubular epithelial cells undergo transdifferentiation of cell phenotypes, transdifferentiating from epithelial cells to myofibroblasts in order to adapt to changes in their microenvironment. $\alpha-S M A$ is a marker of this phenotypic transdifferentiation [15].

There are two Smad3 reaction regions in the $\alpha-$ SMA gene promoter. The expression of a-SMA protein converts the cells into myofibroblasts and synthesizes large amounts of ECM components [16], such as fibronectin (FN) and laminin (LN) [17]. Moreover, TGF $\beta 1$ receptors formed by TGF $\beta 1$ can activate smad2/3, eventually causing a decrease in E-cadherin and an increase in $\alpha-$ SMA [18]. Epithelial cadherin (E-cadherin) reduces renal damage and transdifferentiates into interstitial fibroblasts. The adhesion function between cells is impaired and EMT occurs, causing RIF [19].

Previous studies have revealed that antioxidant treatment has become essential for the treatment of DM and its complications, with many natural agents offering promising effects on DM and its complications based on their antioxidative properties [20,21]. Nath et al [22] demonstrated that $\mathrm{HO}-1$ can promote the production of $\mathrm{CO}$ and bilirubin after catalyzing hemoglobin, which has a protective effect on renal ischemia-reperfusion injury.

Kim et al [23] found that $\alpha 7$ nicotinic acetylcholine receptors in proximal tubular cells induced the expression of $\mathrm{HO}-1$, protecting cells from renal injury. Pan et al [24] also found that $\mathrm{HO}-1$ expression is important in protecting kidneys in preventing cisplatin-induced nephrotoxicity in mice. Our results showed that after administering high glucose levels for $2 \mathrm{~h}$, TGF $\beta 1$ and $\alpha$-SMA increased and E-cadherin decreased, indicating that EMT occurred. After kidney injury, related pathways such as TGF $\beta 1 /$ Smads are activated, $\alpha-S M A$ is expressed, and myofibroblasts are produced, resulting in a large amount of ECM. In addition, the expression of $\mathrm{HO}-1$ increased after intervention with high glucose.

The results of the TS-treated groups showed that after treatment, TGF $\beta 1, \alpha-S M A$, and LN expression decreased, while E-cad expression increased, indicating that the alterations in EMT caused by high glucose levels improved: the expression of $\alpha$-SMA was inhibited, the formation of mesenchymal cells was prevented, and EMT was inhibited. The decrease in LN indicates a decrease in ECM. The expression of $\mathrm{HO}-1$ increased and the number of $\mathrm{HO}-1$ in TS-treated cells increased in comparison to control cells. However, the expression of FN did not decrease 
significantly after intervention with TS, thus further experiments are needed.

\section{CONCLUSION}

These results indicate that Tanshinone IIA inhibits the expression of TGF $\beta 1$ and $\alpha-S M A$, thus affecting the occurrence of EMT, enhances the expression of $\mathrm{HO}-1$, and delays $\mathrm{DN}$ progression. This lends some support for the use of Tanshinone IIA as a potential treatment for delaying DN progression.

\section{DECLARATIONS}

\section{Acknowledgement}

This work was supported by the National Natural Science Foundation of China (nos. 81603544 and 81573888).

\section{Conflict of interest}

No conflict of interest is associated with this work.

\section{Contribution of authors}

We declare that this work was done by the authors named in this article and all liabilities pertaining to claims relating to the content of this article will be borne by the authors.

\section{Open Access}

This is an Open Access article that uses a funding model which does not charge readers or their institutions for access and distributed under the terms of the Creative Commons Attribution License (http://creativecommons.org/licenses/by/ 4.0) and the Budapest Open Access Initiative (http://www.budapestopenaccessinitiative.org/rea d), which permit unrestricted use, distribution, and reproduction in any medium, provided the original work is properly credited.

\section{REFERENCES}

1. Raptis $A E$, Viberti G. Pathogenesis of diabetic nephropathy. Exp Clin Endocrinol Diabetes 2001; 2: 424-437.

2. Liu Y. New insights into epithelial-mesenchymal transition in kidney fibrosis. J Am Soc Nephrol 2010; 21: 212.

3. Kim MK, Maeng YI, Sung WJ, Oh HK, Park JB. Yoon GS. Cho $\mathrm{CH}$. Park KK. The differential expression of TGF$\beta 1, \quad I L K$ and wnt signaling inducing epithelial to mesenchymal transition in human renal fibrogenesis: an immunohistochemical study. Int J Clin Exp Pathol 2013; 6: $1747-1758$

4. Zhai L, Wang $X$. Syringaresinol-di-O- $\beta-D$-glucoside, a phenolic compound from Polygonatum sibiricum, exhibits an antidiabetic and antioxidative effect on a streptozotocin-induced mouse model of diabetes. Mol Med Rep 2018; 18: 5511-5519.

5. Peng $W$, Liu Y, Hu M, Zhang M, Yang J, Liang F, Huang $Q$, Wu C. Toona sinensis: a comprehensive review on its traditional usages, phytochemisty, pharmacology and toxicology. Rev Bras Farmacog 2019; 29: 111-124.

6. Tian $\mathrm{XH}, \mathrm{Wu} \mathrm{JH}$. Tanshinone derivatives: a patent review (January 2006 - September 2012). Expert Opin Ther Pat 2013; 23: 19-29.

7. Feng J, Chen HW, Pi LJ, Wang J. Protective effect of tanshinone IIA against cardiac hypertrophy in spontaneously hypertensive rats through inhibiting the Cys-C/Wnt signaling pathway. Oncotarget 2017; 8: 10161.

8. Shao $Q$, Jiang $C$, Sun $C$, Zhu $W$, Cao D, Feng $Y$, Zhang M. Tanshinone IIA mitigates peritoneal fibrosis by inhibiting EMT via regulation of TGF- $\beta /$ smad pathway. Trop J Pharm Res 2017; 16: 2857-2864.

9. Farag YM, Wakeel JS. Diabetic nephropathy in the Arab Gulf countries. Nephron 2011; 119: c317-c323.

10. Rd FC, Khoury CC, Buller CL, Chen S. Abnormalities in signaling pathways in diabetic nephropathy. Expert Rev Endocrinol Metab 2010; 5: 51-64.

11. Lee SB, Kanasaki K, Kalluri R. Circulating TGF- $\beta 1$ as a reliable biomarker for chronic kidney disease progression in the African-American population. Kidney Int 2009; 76: 10-12.

12. Lan $T$, Liu $W H$, Xie $X$. Berberine suppresses high glucose-induced TGF- $\beta 1$ and fibronectin synthesis in mesangial cells through inhibition of sphingosine kinase 1/AP-1 pathway. Eur J Pharmacol 2012; 697: 165-170.

13. Hu NP, Duan JL, Li HH. Hydroxysafflor yellow a ameliorates renal fibrosis by suppressing TGF- $\beta 1$ induced epithelial-to-mesenchymal transition. Plos One 2016; 11: e0153409.

14. Sato M, Muragaki Y, Saika S, Roberts AB. Targeted disruption of TGF-beta1/Smad3 signaling protects against renal tubulointerstitial fibrosis induced by unilateral ureteral obstruction. J Clin Invest 2003; 112 1486-94.

15. Roach KM, Feghali-Bostwick C, Wulff $H$, Amrani $Y$, Bradding $P$. Human lung myofibroblast TGF $\beta 1$ dependent Smad2/3 signalling is $\mathrm{Ca}(2+)$-dependent and regulated by $\mathrm{KCa} 3.1 \mathrm{~K}(+)$ channels. Fibrogenesis \& Tissue Repair 2015; 8: 5-9.

16. Massagué J. How cells read TGF-beta signals. Nat Rev Mol Cell Biol 2000, 1: 169-178.

17. Chen N, Hao J, Li LS, Li F, Liu SX, Duan HJ. Carboxyterminal modulator protein attenuated extracellular matrix deposit by inhibiting phospho-Akt, TGF- $\beta 1$ and $\alpha-$ SMA in kidneys of diabetic mice. Biochem Biophy Res Comm 2016; 474: 753-760. 
18. Hills CE, Squires PE. TGF-beta1-induced epithelial-tomesenchymal transition and therapeutic intervention in diabetic nephropathy. Am J Nephrol 2010; 31: 68-74.

19. Zeisberg EM, Potenta SE, Sugimoto $H$, Zeisberg $M$. Fibroblasts in kidney fibrosis emerge via endothelial-tomesenchymal transition. J Am Soc Nephrol 2008; 19: 2282.

20. Wang J, Wang L, Lou GH, Zeng HR, Hu J, Huang QW, Peng $W$, Yang $X B$. Coptidis Rhizoma: a comprehensive review of its traditional uses, botany, phytochemistry, pharmacology and toxicology. Pharm Biol 2019; 57: 193-225.
21. Zager RA, Johnson AC, Becker K. Plasma and urinary heme oxygenase-1 in AKI. J Am Soc Nephrol 2012; 23: 1048-1057.

22. Nath KA. The role of renal research in demonstrating the protective properties of heme oxygenase-1. Kidney Int 2013; 84: 3-6.

23. Kim H, Kim SR, Je J, Jeong K. The proximal tubular $\alpha 7$ nicotinic acetylcholine receptor attenuates ischemic acute kidney injury through Akt/PKC signaling-mediated HO-1 induction. Exp Mol Med 2018; 50: 40-49.

24. Pan $H$, Shen $K Z$, Wang $X P, M e n g ~ H Z$. Protective effect of metalloporphyrins against cisplatin-induced kidney injury in mice. Plos One 2014; 9: e86057. 